\title{
George Sand, Nanon
}

\section{Annarosa Poli}

\section{(Q) OpenEdition}

\section{Journals}

\section{Edizione digitale}

URL: http://journals.openedition.org/studifrancesi/7992

DOI: 10.4000/studifrancesi.7992

ISSN: 2427-5856

\section{Editore}

Rosenberg \& Sellier

\section{Edizione cartacea}

Data di pubblicazione: 1 juillet 2009

Paginazione: 419

ISSN: 0039-2944

\section{Notizia bibliografica digitale}

Annarosa Poli, «George Sand, Nanon», Studi Francesi [Online], 158 (LIII | II) | 2009, online dal 30

novembre 2015, consultato il 07 janvier 2021. URL: http://journals.openedition.org/studifrancesi/7992 ; DOI: https://doi.org/10.4000/studifrancesi.7992

Questo documento è stato generato automaticamente il 7 janvier 2021.

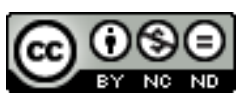

Studi Francesi è distribuita con Licenza Creative Commons Attribuzione - Non commerciale - Non opere derivate 4.0 Internazionale. 


\title{
George Sand, Nanon
}

\author{
Annarosa Poli
}

\section{NOTIZIA}

GEORGE SAND, Nanon, texte intégral établi, présenté et annoté par Nicole MOZET, d'après l'édition originale (1872), Saint-Cyr-sur-Loire, Christian Pirot, 2005, pp. 305.

1 Nanon, uno degli ultimi romanzi di George Sand, è un testo ormai dimenticato. Nicole Mozet nel 1987 ne aveva dato un'edizione, da lungo tempo esaurita. Oggi, sempre grazie alla stessa curatrice, abbiamo il piacere di avere una nuova edizione di questo bel romanzo insieme ad un'altra curata da Nicole SAVY che presenta l'opera sotto un altro punto di vista.

2 La storia di Nanon è particolarmente emozionante e originale. L'eroina, una contadina del Berry che sposerà il marchese Émilien de Franqueville, racconta la sua vita a partire dall'infanzia e dalla giovinezza prima e durante la Rivoluzione francese. Il romanzo narra la storia di una ragazza coraggiosa, intelligente, dotata di una grande generosità e di un notevole senso pratico degli affari. Questa giovane che possedeva soltanto delle grandi qualità e una pecora da allevare giungerà a ottenere la ricchezza grazie al suo lavoro e ad un insieme di circostanze fortunate, ma senza alcuna speculazione. È una storia d'amore che unisce la pastorella a un giovane onesto di nobile famiglia, che però lo ha abbandonato alla sua sorte. Il loro amore non ha nulla di passionale, ma è piuttosto un'unione profonda di anime che il destino unisce contro i pregiudizi sociali dell'Ancien Régime. Nanon è pure un romanzo storico nel quale la Rivoluzione francese è evocata attraverso quello che potevano comprendere gli abitanti di una povera regione campestre, lontana dal centro degli avvenimenti rivoluzionari. I protagonisti si trovano a combattere con una vita quotidiana difficile e, a volte pericolosa, ma la affrontano con molta fermezza. Émilien, sequestrato dal tribunale rivoluzionario, viene liberato grazie a Nanon. Si rifugiano insieme in un luogo nascosto e magico di Valcreux, dove aspettano la fine del Terrore. Il giovane si arruola allora nell' esercito repubblicano, ritorna dalla guerra però senza il suo braccio destro. Raccontata in modo stringato, 
questa storia non ha nulla di romantico. Si distingue anche dagli altri romanzi sandiani perché unisce insieme diverse caratteristiche narrative.

Romanzo di formazione e nello stesso tempo romanzo storico, descrive la vita particolarmente fuori dal comune di una contadina che riesce ad avere un'ottima educazione e il benessere con i suoi propri mezzi. È un romanzo di formazione di una personalità che acquista la sua pienezza attraverso la sua luminosa femminilità. La romanziera espone anche le sue idee sulla Rivoluzione, la Repubblica e il Terrore. All'indomani della guerra del 1870 e della Comune di Parigi, Sand esprime il suo rifiuto degli eccessi della violenza che, secondo lei, hanno deviato e annullato la Rivoluzione del 1789.

4 Il racconto di Nanon è caratterizzato da una limpidezza particolare, da una semplicità che non troveremo spesso negli altri romanzi sandiani e che ricorda la perfezione dello stile della Mare au diable. 